\title{
Research on the Transformation of Nitrogen during Hydrothermal Carbonization of Sludge
}

\author{
Ying Sun ${ }^{1, a}$, Qian Yang ${ }^{1}$ \\ ${ }^{1}$ School of Environmental and Chemical Engineering, Shanghai University Shanghai, 200444,China
}

\begin{abstract}
The nitrogen in the sludge mainly exists in the form of inorganic nitrogen and organic nitrogen. In this paper, the transformation of nitrogen during the hydrothermal carbonization of sludge was studied. The results showed that during the hydrothermal carbonization of the sludge, both the total nitrogen and the inorganic nitrogen in hydrochar decrease with the increase of the carbonization temperature. The reason is that part of the inorganic nitrogen compounds in the sludge undergoes thermal decomposition to release $\mathrm{NH}_{3}$, and some organic nitrogen will be hydrolyzed to produce ammonia nitrogen into the liquid phase.
\end{abstract}

\section{INTRODUCTION}

The sludge produced by sewage treatment plants has soared worldwide in recent years. At present, sludge production in China is estimated to reach 6 million dry tons every year [1]. Sludge is rich in nutrients (nitrogen, phosphorus, potassium, etc.) and available organics (such as protein, sugar, fat, etc.). The nitrogen in the sludge mainly exists in the organic and inorganic forms. The organic nitrogen is mainly nitrogen-containing functional groups, such as protein nitrogen, pyridine nitrogen, pyrrole nitrogen, etc, while the inorganic nitrogen is mainly ammonium nitrogen, nitrate nitrogen and nitrite nitrogen[2].

Hydrothermal carbonization is a thermochemical treatment method that converts solid biomass to carbon-enriched solid carbon materials at a temperature of $180{ }^{\circ} \mathrm{C}$ to $350{ }^{\circ} \mathrm{C}$ and a pressure of $2-10 \mathrm{MPa}$ in the presence of liquid water [3]. After the sludge is hydrothermally carbonized, the produced hydrochar may have many kinds of applications. In particular, the sludge is rich in nitrogen elements, which can be transformed to form inorganic nitrogen or redox functional groups after hydrothermal carbonization. The conversion of the nitrogen elements has an important influence on subsequent reuse. For example, sludge hydrochar can be used as a soil conditioner due to that inorganic nitrogen, such as ammonium nitrogen and nitrate nitrogen, is available for plant absorption and utilization. In addition, the sludge hydrochar also has a good application in adsorption, and some of its surface nitrogen, oxygen and sulfur functional groups can be used to adsorb heavy metals in water [4]. The sludge hydrochar can also be used as fuel. When the sludge is hydrothermally carbonized, its calorific value will increase [5]. However,

\footnotetext{
${ }^{*}$ Corresponding author: ${ }^{a}$ syshtj@sina.com
}

nitrogen in the combustion process may form some NOx when the sludge hydrochar is used as fuel, which is a problem to be considered during thus application. In summary, the changes of nitrogen content and form have an important influence on the application of sludge hydrochar. It is of great significance to study the transformation of nitrogen during sludge hydrothermal carbonization. In this paper, the changes of nitrogen content and form in solid phases were determined after hydrothermal carbonization of sludge under different conditions, and the possible conversion pathways of nitrogen were proposed.

\section{METHODS}

\subsection{Sludge samples}

The dewatered sludge samples used in this study were taken from a sewage treatment plant in Shanghai. After the sludge samples were collected, they were baked in an oven at $105{ }^{\circ} \mathrm{C}$ for two days, then ground through 100 mesh screens and sealed.

\subsection{Experimental method}

Weigh $10 \mathrm{~g}$ of original sludge sample into a beaker, add $60 \mathrm{ml}$ of deionized water, stir it with a magnetic stirrer for $1 \mathrm{~h}$. Then pour it into a hydrothermal dish, pass nitrogen gas at a flow rate of $100 \mathrm{ml} / \mathrm{min}$ for $15 \mathrm{~min}$ to exhaust the oxygen in the system, and then quickly cap and place it in a high-pressure reactor for completely sealed. Then put it in a constant temperature drying oven and the temperature is raised at a certain rate. When the temperature reaches a certain degree, the temperature is fixed for a period of time.

After reaching the carbonization time, remove the 
autoclave and cool it to room temperature, then pour it into a $100 \mathrm{ml}$ centrifuge tube and centrifuge it in a centrifuge at $3000 \mathrm{r} / \mathrm{min}$ for $10 \mathrm{~min}$. The liquid phase product is transferred to a centrifuge tube and stored in a refrigerator. At the same time, the solid product was dried in a thermostatic drying oven at $105{ }^{\circ} \mathrm{C}$ to a constant weight. After that, the resulting solid product was ground through a 100 mesh sieve and stored for future use.

The total nitrogen content in hydrochar was determined by alkaline potassium persulfate oxidation-ultraviolet spectrophotometry. The hydrochar sample was digested by high pressure in the presence of potassium persulfate to convert nitrite, ammonium, and organic nitrogen into nitrate. The absorbance was measured at $220 \mathrm{~nm}$ and $275 \mathrm{~nm}$ on an ultraviolet spectrophotometer, and the total nitrogen of the sample was calculated. The ammonium nitrogen content in hydrochar was determined by the method of nessler's reagent. The basic solution of mercury iodide and potassium iodide reacts with ammonia to produce a light yellow-brown colloidal compound. Its color intensity is proportional to the ammonia nitrogen content, and the absorbance is usually measured at a wavelength of 410 $\mathrm{nm}-425 \mathrm{~nm}$ to calculate the content of ammonium nitrogen in hydrochar.

\section{RESULTS AND DISCUSSION}

\subsection{The proportion of different forms of nitrogen in sludge samples}

Table 1. The proportion of each form of nitrogen in sludge samples.

\begin{tabular}{|c|c|}
\hline & Sludge samples \\
\hline Total nitrogen $(\%)$ & $100 \%$ \\
\hline Inorganic nitrogen & $12.00 \%$ \\
\hline Organic nitrogen & $88 \%$ \\
\hline
\end{tabular}

It can be seen from Table 1 that the forms of nitrogen in sludge mainly include inorganic nitrogen (mainly ammonium nitrogen and nitrate nitrogen) and organic nitrogen (mainly protein nitrogen, pyrrolic nitrogen, and pyridine nitrogen). The content of organic nitrogen accounts for $88 \%$ of the total nitrogen in the sludge. This is because organic nitrogen mainly contains protein nitrogen, pyrrole- $\mathrm{N}$ and pyridine- $\mathrm{N}$. The sludge contains a lot of microorganisms, and the microbial cells themselves contain a lot of protein where the protein nitrogen is derived. Inorganic nitrogen accounted for $12.00 \%$ of the total nitrogen in the sludge. Among them, pyrrole nitrogen and pyridine nitrogen are derived from the decomposition products of nucleic acids during the carbonization of sludge.

\subsection{Analysis of nitrogen in sludge hydrothermal product}
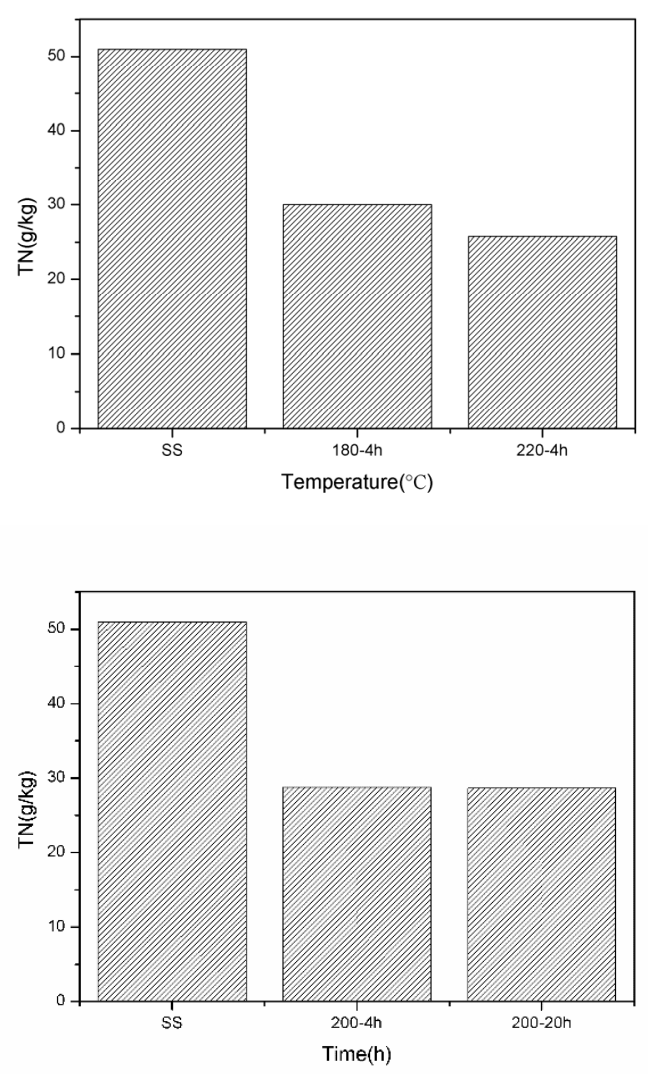

Figure 1. Total nitrogen content in raw sludge and its hydrochar under different carbonization conditions. As shown in figure 1, the total nitrogen content in the raw sludge was $50.98 \mathrm{~g} / \mathrm{kg}$. After hydrothermal carbonization, the total nitrogen content decreased. With the carbonization temperature rising from $180{ }^{\circ} \mathrm{C}$ to $220{ }^{\circ} \mathrm{C}$, the total nitrogen content in the hydrochar was decreased from $30.00 \mathrm{~g} / \mathrm{kg}$ to $25.74 \mathrm{~g} / \mathrm{kg}$. With the increase of the carbonization time from $4 \mathrm{~h}$ to $20 \mathrm{~h}$, the total nitrogen content is basically unchanged. The reason is that in the process of hydrothermal carbonization, the inorganic nitrogen in the sludge undergoes thermal decomposition to release $\mathrm{NH}_{3}$, and the organic nitrogen in the sludge is decomposed into ammonia nitrogen and enters to the liquid phase. With the increase of carbonization temperature, more inorganic nitrogen is decomposed due to the increase of its gas yield. Therefore the total nitrogen content is decreasing.

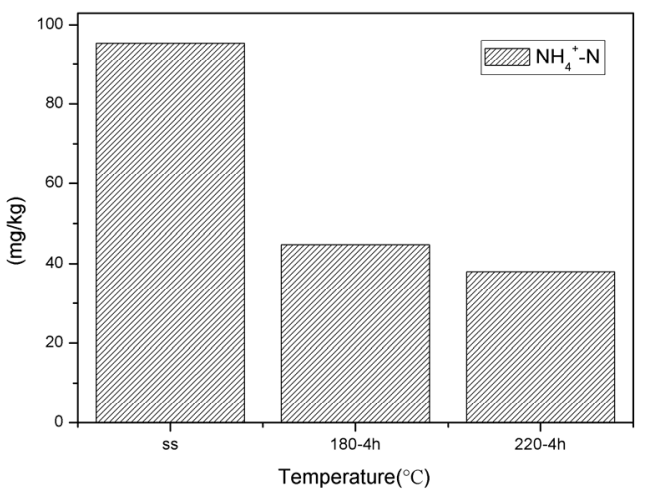




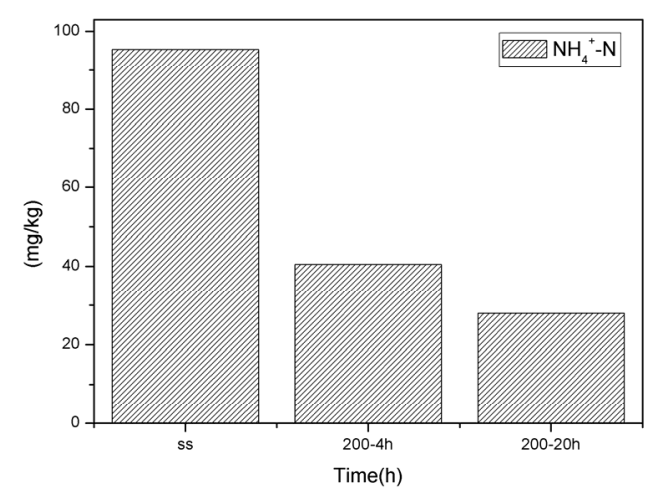

Figure 2. $\mathrm{NH}_{4}{ }^{+}-\mathrm{N}$ content in raw sludge and its hydrochar under different carbonization conditions.

As shown in figure 2, the content of $\mathrm{NH}_{4}{ }^{+}-\mathrm{N}$ in raw sludge was $95.37 \mathrm{mg} / \mathrm{kg}$. The inorganic nitrogen content decreased after hydrothermal carbonization. With the hydrothermal carbonization temperature rising from $180{ }^{\circ} \mathrm{C}$ to $220{ }^{\circ} \mathrm{C}$, the content of $\mathrm{NH}_{4}{ }^{+}-\mathrm{N}$ in hydrochar decreased from $44.75 \mathrm{mg} / \mathrm{kg}$ to $37.99 \mathrm{mg} / \mathrm{kg}$. And with the increase of the carbonization time from $4 \mathrm{~h}$ to $20 \mathrm{~h}$, the content of $\mathrm{NH}_{4}^{+}-\mathrm{N}$ in hydrochar decreased. The reason is that some inorganic nitrogen compounds in the sludge undergo thermal decomposition to release $\mathrm{NH}_{3}$ at a temperature of $100{ }^{\circ} \mathrm{C}$ to $300{ }^{\circ} \mathrm{C}$. With the increase of the carbonization temperature and carbonization time, the gas yield increases. Therefore the inorganic nitrogen content in the hydrochar tends to decrease.

\section{Conclusion}

Most of the nitrogen in the sludge is organic nitrogen, and it contains a small amount of inorganic nitrogen (mainly ammonium nitrogen and nitrate nitrogen). After hydrothermal carbonization of the sludge, the total nitrogen and inorganic nitrogen content in the solid phase are reduced. The reason is that during the hydrothermal carbonization of the sludge, part of the inorganic nitrogen undergoes thermal decomposition to release $\mathrm{NH}_{3}$, and some organic nitrogen will be hydrolyzed to produce ammonia nitrogen into the liquid phase.

\section{References}

1. Liu, F.W., Zhou, J, Wang, D.ZH., Zhou, L.X.J. Environ. Sci.24, 1403-1410 (2012)

2. Tian, Y, Zhang, J, Zuo, W, Chen, L, Cui, Y.N., Tan, T. J. Environ. Sci. Technol. 47, 3498-3505 (2013)

3. Mumme, J, Eckervogt, L, Pielert, J, Diakité, M, Rupp, F, Kern, J. Bioresource. Technol. 102, 9255-9260 (2011).

4. Liu,ZH.G., Zhang, F.SH. J. Desalination. 267, 101-106 (2011)

5. He, C, Giannis, A, Wang, J. Y. J. Appl. Energ. 111, 257-266 (2013) 